\title{
Accurate determination of interface trap state parameters by admittance spectroscopy in the presence of a Schottky barrier contact: Application to ZnO-based solar cells
}

Andrew T. Marin, Kevin P. Musselman, and Judith L. MacManus-Driscoll

Citation: Journal of Applied Physics 113, 144502 (2013); doi: 10.1063/1.4799633

View online: https://doi.org/10.1063/1.4799633

View Table of Contents: http://aip.scitation.org/toc/jap/113/14

Published by the American Institute of Physics

\section{Articles you may be interested in}

Determination of defect distributions from admittance measurements and application to $\mathrm{Cu}(\mathrm{In}, \mathrm{Ga}) \mathrm{Se}_{2}$ based heterojunctions

Journal of Applied Physics 80, 4411 (1996); 10.1063/1.363401

Interpretation of admittance, capacitance-voltage, and current-voltage signatures in $\mathrm{Cu}(\mathrm{In}, \mathrm{Ga}) \mathrm{Se}_{2}$ thin film solar cells

Journal of Applied Physics 107, 034509 (2010); 10.1063/1.3277043

Investigation of defects by admittance spectroscopy measurements in poly (3-hexylthiophene):(6,6)-phenyl $\mathrm{C}_{61^{-}}$ butyric acid methyl ester organic solar cells degraded under air exposure

Journal of Applied Physics 110, 094509 (2011); 10.1063/1.3658023

Admittance spectroscopy of impurity levels in Schottky barriers

Journal of Applied Physics 46, 2204 (1975); 10.1063/1.321865

Bulk and metastable defects in $\mathrm{CuIn}_{1-\mathrm{X}} \mathrm{Ga}_{x} \mathrm{Se}_{2}$ thin films using drive-level capacitance profiling Journal of Applied Physics 95, 1000 (2004); 10.1063/1.1633982

Defect density and dielectric constant in perovskite solar cells

Applied Physics Letters 105, 153502 (2014); 10.1063/1.4897329

This article may be downloaded for personal use only. Any other use requires prior permission of the author and AIP Publishing. The following article appeared in Marin, A. T., Musselman, K. P., \& MacManus-Driscoll, J. L. (2013).

Accurate determination of interface trap state parameters by admittance spectroscopy in the presence of a Schottky barrier contact: Application to ZnO-based solar cells. Journal of Applied Physics, 113(14), 144502 and may be found at https://doi.org/10.1063/1.4799633

\section{PHYSICS TODAY}

\section{WHITEPAPERS}

MANAGER'S GUIDE

Accelerate R\&D with

Multiphysics Simulation

\section{READ NOW}

PRESENTED BY

И口 $\subset$ MSOL 


\title{
Accurate determination of interface trap state parameters by admittance spectroscopy in the presence of a Schottky barrier contact: Application to ZnO-based solar cells
}

\author{
Andrew T. Marin, ${ }^{1}$ Kevin P. Musselman, ${ }^{2}$ and Judith L. MacManus-Driscoll ${ }^{1, \text { a) }}$ \\ ${ }^{1}$ Materials Science \& Metallurgy, University of Cambridge, Cambridge CB2 3QZ, United Kingdom \\ ${ }^{2}$ Cavendish Laboratory, University of Cambridge, Cambridge CB3 OHE, United Kingdom
}

(Received 29 January 2013; accepted 21 March 2013; published online 9 April 2013)

\begin{abstract}
This work shows that when a Schottky barrier is present in a photovoltaic device, such as in a device with an ITO/ZnO contact, equivalent circuit analysis must be performed with admittance spectroscopy to accurately determine the pn junction interface recombination parameters (i.e., capture cross section and density of trap states). Without equivalent circuit analysis, a Schottky barrier can produce an error of $\sim 4$-orders of magnitude in the capture cross section and $\sim 50 \%$ error in the measured density of trap states. Using a solution processed $\mathrm{ZnO} / \mathrm{Cu}_{2} \mathrm{O}$ photovoltaic test system, we apply our analysis to clearly separate the contributions of interface states at the pn junction from the Schottky barrier at the ITO/ZnO contact so that the interface state recombination parameters can be accurately characterized. This work is widely applicable to the multitude of photovoltaic devices, which use $\mathrm{ZnO}$ adjacent to ITO. (C) 2013 American Institute of Physics.
\end{abstract} [http://dx.doi.org/10.1063/1.4799633]

\section{INTRODUCTION}

Recombination at interface states is highly disabling to the performance of a photovoltaic device and is particularly prevalent in many new-age device designs. ${ }^{1,2}$ In order to better understand the impact of interface recombination on a device's performance, it is critical to determine the interface trap state density, capture cross section, and interface Fermi level position. These parameters directly influence the recombination velocity and dark saturation current, which impacts the photovoltaic device behavior. ${ }^{3}$

Admittance spectroscopy is a highly valuable technique that can be used to obtain the recombination parameters for a trap state. ${ }^{4-8}$ These parameters can be determined by correlating a trap state's peak in the admittance data (usually plotted as the conductance ${ }^{9}$ or differential capacitance ${ }^{7}$ ) with temperature. Admittance spectroscopy has been used to examine the bulk and interface state densities of multiple photovoltaic devices, ${ }^{4-6,10}$ such as those employing CIGS as an absorber layer.

In addition, a Schottky barrier contact is known to produce a peak in the admittance data that resembles a trap state ${ }^{8,11,12}$ Schottky barrier contacts commonly exist in photovoltaic devices at the interface between a transparent conductor (e.g., ITO) and an n-type window layer (e.g., $\mathrm{ZnO}$ and $\left.\mathrm{TiO}_{2}\right) .{ }^{1,13}$ These contacts are ubiquitously used in multiple types of solar cells including bulk-heterojunction (e.g., ITO/ ZnO/P3HT:PCBM) ${ }^{14}$ thin film (e.g., ITO/ZnO/CdS/CIGS), ${ }^{15}$ and quantum dot (e.g., ITO/ZnO/PbS) ${ }^{16}$ devices. In a device with interface states and a Schottky barrier, two peaks will be observed in the admittance data. While the admittance behavior of the Schottky barrier contact is known, ${ }^{11,12}$ the error

\footnotetext{
${ }^{\text {a) }}$ Author to whom correspondence should be addressed. Electronic mail: jld35@cam.ac.uk
}

induced by the Schottky barrier on a true trap state's recombination parameters has not been assessed.

A need for low-cost photovoltaics has pushed research towards solution processing at low temperatures and atmospheric pressure, but these cells are often hindered by interface defect states. These devices also often employ an ITO/ $\mathrm{ZnO}$ contact. It is thus essential to understand the impact of the ITO/ZnO Schottky barrier on the analysis of interface states so that the electrical behavior of the device can be properly characterized.

We employ equivalent circuit analysis to understand the impact of the Schottky barrier on a trap state's recombination parameters as determined by admittance spectroscopy. For equivalent circuit analysis, an electrical circuit is created to describe the physical parameters in a device. For example, a parallel RC circuit can be used to describe a Schottky barrier contact. ${ }^{1}$ While equivalent circuit analysis is rudimentary to the development of all dielectric techniques (impedance, admittance, modulus, and dielectric spectroscopy), ${ }^{17}$ it is rarely ${ }^{18}$ employed with admittance spectroscopy. As we show in this investigation, equivalent circuit analysis is a critical supplement to admittance spectroscopy when a Schottky barrier is present in a device.

We show the benefit of the combination of techniques when analyzing the interface recombination parameters of a solution deposited $\mathrm{ZnO} / \mathrm{Cu}_{2} \mathrm{O}$ device with an $\mathrm{ITO} / \mathrm{ZnO}$ Schottky barrier contact. Fully electrodeposited $\mathrm{ZnO} / \mathrm{Cu}_{2} \mathrm{O}$ has gained recent interest as a low-cost photovoltaic device but has so far failed to reach its theoretical efficiency. ${ }^{1,19-23}$ Many researchers attribute poor device performance of $\mathrm{ZnO} /$ $\mathrm{Cu}_{2} \mathrm{O}$ to acceptor states at the heterojunction interface where electrons from the $\mathrm{ZnO}$ can become trapped and eventually recombine with holes from the $\mathrm{Cu}_{2} \mathrm{O}{ }^{1,24-26}$ The interface states are believed to originate from the lattice mismatch of the two materials ${ }^{27}$ and from $\mathrm{ZnO}$ dissolution in the basic 
$\mathrm{Cu}_{2} \mathrm{O}$ deposition solution. ${ }^{1}$ In addition, electrodeposited $\mathrm{ZnO}$ has a high surface defect density due to $\mathrm{Zn}(\mathrm{OH})_{2}$ formation which has been shown to degrade the performance of $\mathrm{ZnO} /$ bulk-heterojunction cells ${ }^{14}$ and is expected to contribute to the interface trap state density in $\mathrm{ZnO} / \mathrm{Cu}_{2} \mathrm{O}$ as well. While researchers have discussed the origin of the interface trap states, the recombination parameters of this device have not been measured.

This investigation is broken into 4 parts. We first examine the theory of using admittance spectroscopy to measure interface recombination parameters (Sec. III A). We then analyze how a Schottky barrier can alter the apparent trap state's differential capacitance response (Sec. III B) and show the significant error in the recombination parameters if the Schottky barrier is not subtracted (Sec. III C). Finally, in Sec. IV we employ the combination of equivalent circuit analysis and admittance to accurately measure the density of trap states and capture cross section of a $\mathrm{ZnO} / \mathrm{Cu}_{2} \mathrm{O}$ device for the first time.

\section{EXPERIMENTAL}

Glass/ITO substrates from Präzisions Glas \& Optik were cleaned in an ultrasonic bath in water, acetone, and isopropanol for $15 \mathrm{~min}$ each. $\mathrm{ZnO}$ films were grown on the ITO via potentiostatic deposition at $-0.85 \mathrm{~V}$ vs a $\mathrm{Ag} / \mathrm{AgCl}$ (saturated $\mathrm{KCl})$ reference electrode, ${ }^{28}$ in a $0.08 \mathrm{M} \mathrm{Zn}\left(\mathrm{NO}_{3}\right)_{2}$ solution with $15 \%$ volume ethanol at a temperature of $70 \pm 1{ }^{\circ} \mathrm{C}$. Films were grown to an approximate thickness of $500 \mathrm{~nm}$. $\mathrm{Cu}_{2} \mathrm{O}$ was deposited galvanostatically onto the $\mathrm{ZnO}$ films at $-1.0 \mathrm{~mA}$ $\mathrm{cm}^{-2}$ from an aqueous solution of $0.04 \mathrm{M} \mathrm{Cu}_{2} \mathrm{SO}_{4} / 3 \mathrm{M}$ lactic acid at $40^{\circ} \mathrm{C}^{20}$ The $\mathrm{pH}$ was adjusted to 12.6 by adding $4 \mathrm{M}$ $\mathrm{NaOH}$. Films were grown to a thickness of $3 \mu \mathrm{m}$. Gold contacts were evaporated on the $\mathrm{Cu}_{2} \mathrm{O}$ using a $\mathrm{BOC}$ Edwards Auto 306 resistance evaporator. The device area was $0.15 \mathrm{~cm}^{2}$.

The trap state density was examined by admittance spectroscopy. Samples were analyzed from $40 \mathrm{~Hz}$ to $1 \mathrm{MHz}$ with a $20 \mathrm{mV}$ AC voltage using an Agilent $4294 \mathrm{~A}$ impedance analyzer. The temperature was controlled using a hot plate, and samples were kept in the dark for $48 \mathrm{~h}$ prior to testing the device in order to empty states filled from photogenerated charges. The LEVMw complex nonlinear least squares fitting software was used to fit the admittance data for equivalent circuit analysis. ${ }^{17}$

The carrier density of electrodeposited $\mathrm{Cu}_{2} \mathrm{O}$ and $\mathrm{ZnO}$ has to have previously been measured to be $<10^{14} \mathrm{~cm}^{-3}$ and $>10^{17} \mathrm{~cm}^{-3}$, respectively. ${ }^{19,21}$ This 3-4 order of magnitude difference creates an $\mathrm{n}^{+}-\mathrm{p}$ structure where the depletion width of the $\mathrm{ZnO}$ region is negligible $(\sim 1 \mathrm{~nm})$ in comparison to the depletion width of $\mathrm{Cu}_{2} \mathrm{O}(1.5-3 \mu \mathrm{m})$, considering the built-in potential $(0.4-0.7 \mathrm{eV})$ and the dielectric constants $\left(7 \varepsilon_{0} \mathrm{Cu}_{2} \mathrm{O}, 8 \varepsilon_{0} \mathrm{ZnO}\right)$ of the two materials. ${ }^{21,24}$

\section{THEORY AND MODELING}

\section{A. Measuring interface states by admittance spectroscopy}

During an admittance spectroscopy measurement, an applied AC voltage oscillates the Fermi level of the device under test at a given frequency. From the measured admittance, the capacitance which relates to the charge density of the semiconductor region being analyzed is calculated. For an abrupt pn junction with a p-region carrier density much less than the $n$-region carrier density $\left(n^{+}-p\right.$ junction), charges in the valence band will only contribute to the measured capacitance response if they exist at a position in the junction where the difference between the Fermi level and valence band energy is small enough for the charges to follow the oscillation, depicted by the shaded region in Figure 1.

Equation (1) describes the relationship between the measurement frequency $(\omega)$ and the energy difference $\left(\mathrm{E}_{\omega}\right)$ at a position $\mathrm{x}_{\omega}$ in the junction ${ }^{7}$

$$
\omega=2 N_{V} v_{t h} \sigma_{c} e^{\left(-E_{\omega} / k T\right)}=\xi T^{2} e^{\left(-E_{\omega} / k T\right)} .
$$

When sweeping across a range of frequencies, an increase in capacitance will occur at the location corresponding to the position that a trap state crosses the Fermi level $\left(\mathrm{x}_{0}\right.$ in Figure 1). ${ }^{4,7,29}$ A differential capacitance plot $(\omega \cdot \mathrm{dC} / \mathrm{d} \omega$ versus $\omega)$ will result in a peak at the emission frequency $\left(\omega=\omega_{0}\right)$ of the trap state. If the measurement is performed for a range of temperatures (T), an Arrhenius plot of Eq. (1) can reveal the energy position $\left(\mathrm{E}_{\omega}=\mathrm{E}_{0}\right)$ and emission prefactor $\left(\xi=\xi_{0}\right)$ of a trap state. ${ }^{7}$ The emission prefactor represents the temperature independent parts of the effective density of states for the valence band $\left(\mathrm{N}_{\mathrm{V}}\right)$, the thermal velocity $\left(v_{\text {th }}\right)$, and the capture cross section $\left(\sigma_{\mathrm{c}}\right)$.

In order to differentiate bulk from interfacial trap states, admittance measurements should be performed at different biases. The energy of the trap state $\left(\mathrm{E}_{0}\right)$ will be equal to the difference between the Fermi level and the valence band at the location $\mathrm{x}_{0}$. Bulk states are generally energetically discrete. Thus, their trap state energy should be bias

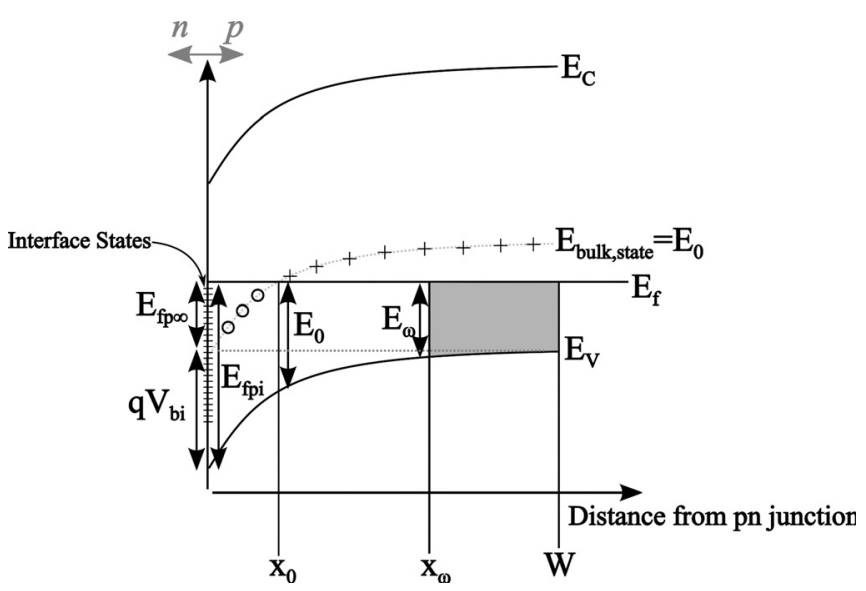

FIG. 1. Schematic of a band diagram of the $\mathrm{p}$-side of an abrupt $\mathrm{n}^{+}-\mathrm{p}$ junction (such as in $\mathrm{ZnO} / \mathrm{Cu}_{2} \mathrm{O}$ ). The shaded region represents the region contributing to the capacitance when measuring at a frequency $(\omega)$ during admittance spectroscopy. The frequency translates into an energy $\left(\mathrm{E}_{\omega}\right)$ which represents the difference between the Fermi level and the valence band at a location $\left(\mathrm{x}_{\omega}\right)$. Here, a bulk trap state is shown to exist at an energy $\left(\mathrm{E}_{0}\right)$ above the valence band and cross the Fermi level at a position $\left(\mathrm{x}_{0}\right)$. A trap state will only contribute to the capacitance response if the frequency is low enough to encompass a region stretching to $\mathrm{x}_{0}$ from the depletion width edge $(\mathrm{W})$. Additionally, it can be seen that the energy at the interface $\left(\mathrm{E}_{\mathrm{fpi}}\right)$ is equal to the built-in potential energy $\left(\mathrm{qV}_{\mathrm{bi}}\right)$ plus the bulk Fermi level position $\left(\mathrm{E}_{\mathrm{fp} \infty}\right)$. 
independent. $^{29,30}$ Conversely, interface states will correspond to the interface Fermi level position $\left(\mathrm{E}_{\mathrm{fpi}}=\mathrm{E}_{0}=\mathrm{E}_{\omega}\right)$ which is defined by

$$
E_{f p i}=E_{f p \infty}+q V_{b i} .
$$

In this equation, $\mathrm{E}_{\mathrm{fp} \infty}$ is the bulk Fermi level position and $\mathrm{V}_{\mathrm{bi}}$ is the built-in potential. Since $\mathrm{V}_{\mathrm{bi}}$ varies with bias, $\mathrm{E}_{\mathrm{fpi}}$ will also be bias dependent, ${ }^{7,29,30}$ as long as the Fermi level is not pinned at the interface. ${ }^{4}$

Equation (3) can be used to determine the density of interface trap states from the device area (A) and trap state capacitance $\left(C_{t}\right)$, which is equivalent to $-2 \omega \mathrm{dC} / \mathrm{d} \omega$ upon differentiation of the equivalent circuit model for a pn junction containing interface states (discussed more in Sec. III B). ${ }^{9}$ Subsequently, Eq. (1) can be used to transform the frequency into an energy axis

$$
N_{t}\left(E_{\omega}\right)=\frac{C_{t}}{q^{2} A}=\frac{-2 \omega}{q^{2} A} \frac{d C}{d \omega} .
$$

Recombination at interface states can dictate the behavior of the pn junction diode. ${ }^{2}$ For an $n^{+}-p$ junction, electrons from the n-material will become trapped at interface states. Recombination will therefore be limited by holes from the p-material finding a filled trap state at the interface. The resulting saturation current density summarizing this mechanism is given $b^{3}$

$$
J_{p n}^{0}=q p_{i f} S,
$$

where $\mathrm{S}$ is the recombination velocity defined by

$$
S=\sigma_{c} v_{t h} N_{t}
$$

and $\mathrm{p}_{\mathrm{i}}$ is the density of holes at the interface defined by

$$
p_{i}=N_{V} e^{-q E_{f p i} / k T}
$$

The saturation current density (Eq. (4)) can then be calculated from the admittance results using the capture cross section and thermal velocity (Eq. (1)), the interface Fermi level energy (Eq. (2)), and the interface state charge density which can be obtained by integrating the density of states (Eq. (3)) in energy.

\section{B. Influence of a Schottky barrier contact on differential capacitance}

In Sec. III A, we described how a differential capacitance plot $(\omega \mathrm{dC} / \mathrm{d} \omega$ vs. $\omega)$ can be used to obtain the interface trap state recombination parameters. One disadvantage of this plot is the blind assessment of the "trap" state peaks. Other researchers ${ }^{11,12,31}$ have shown that a Schottky barrier contact can also produce a peak alongside an apparent trap state peak in a differential capacitance plot. What has not been discussed is the error induced by the Schottky barrier contact on the apparent trap state's peak magnitude and frequency, which are used to calculate the recombination parameters.

To assess this error, we consider the equivalent circuit model in Figure 2. Capacitor $\left(\mathbf{C}_{\mathbf{j}}\right)$ is the junction capacitance

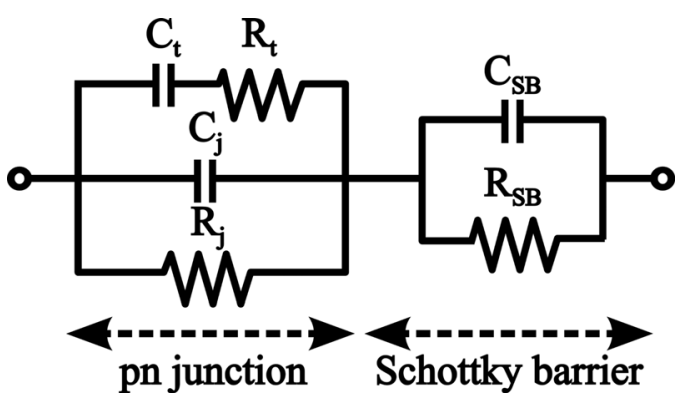

FIG. 2. Equivalent circuit model of a pn junction with a trap state in series with a Schottky barrier contact. $C_{j}$ is the junction capacitance and $R_{j}$ is the parallel resistance of the pn junction depletion region. $C_{t}$ is the trap state capacitance and $R_{t}$ is the resistance to recombination. $C_{S B}$ is the capacitance and $\mathrm{R}_{\mathrm{SB}}$ is the parallel resistance of the Schottky barrier depletion region.

representing free carriers in the depletion region and $R_{j}$ is the parallel shunt resistance. A third branch is shown which contains the trap state capacitance (i.e., $C_{t} \propto$ density of trap states-Eq. (3)) and the resistance to recombination $\left(R_{t}\right)$. In the second section, $\mathrm{C}_{\mathrm{SB}}$ is the capacitance and $\mathrm{R}_{\mathrm{SB}}$ is the parallel resistance across the Schottky barrier depletion region. The total capacitance as a function of frequency for the model in Figure 2 is derived in Appendix A.

Figure 3(a) shows a modeled differential capacitance plot for a device with a trap state in the absence of a Schottky barrier contact and two cases for devices with a trap state in the presence of a Schottky barrier. The differential capacitance in the absence of the Schottky barrier has one peak at frequency $\omega_{0} \sim 2.5 \times 10^{4} \mathrm{rad} \mathrm{s}^{-1}$ and a peak magnitude of $\mathrm{P}=4.5 \times 10^{-9} \mathrm{~F} \mathrm{~cm}^{-2}$ (i.e., $\mathrm{C}_{\mathrm{t}} / 2-\mathrm{Eq}$. (3)). When the Schottky barrier is added to the model, many different scenarios exist depending on the relative magnitude of $\mathrm{C}_{\mathrm{j}}$ vs. $\mathrm{C}_{\mathrm{t}}$ vs. $\mathrm{C}_{\mathrm{SB}}$ and $\tau_{\mathrm{j}}$ vs $\tau_{\mathrm{t}}$ vs $\tau_{\mathrm{SB}}$ where $\tau_{\mathrm{i}}=\mathrm{R}_{\mathrm{i}} \mathrm{C}_{\mathrm{i}}$.

We consider two plausible cases: Case $1\left[\mathrm{C}_{\mathrm{t}}>\mathrm{C}_{\mathrm{SB}}>\mathrm{C}_{\mathrm{j}}\right.$, $\left.\tau_{\mathrm{t}}>\tau_{\mathrm{SB}}>\tau_{\mathrm{j}}\right]$ and Case $2\left[\mathrm{C}_{\mathrm{SB}}>\mathrm{C}_{\mathrm{t}}>\mathrm{C}_{\mathrm{j}}, \tau_{\mathrm{SB}}>\tau_{\mathrm{t}}>\tau_{\mathrm{j}}\right]$. Case 1 represents a device with interface states and a Schottky barrier in the $\mathrm{n}^{+}$-material which has a doping density that gives a moderately large $(100-500 \mathrm{~nm})$ Schottky barrier depletion width but is less than the depletion width of the pn junction. Case 2 represents a device with an equal number of interface trap states as Case 1 but has a higher carrier concentration, higher dielectric constant, or lower barrier height in the Schottky barrier depletion region than Case 1 such that $\mathrm{C}_{\mathrm{SB}}$ is larger than $\mathrm{C}_{\mathrm{t}}$.

For Case 1, the differential capacitance plot has two peaks as shown in Figure 3(a). Both peaks are composed of contributions from the trap state and Schottky barrier. The apparent trap state peak $\left(\omega_{0}{ }^{\prime}, \mathrm{P}^{\prime}\right)$ is much lower in magnitude and frequency than the true trap state peak $\left(\omega_{0}, \mathrm{P}\right)$. The reduction of the trap state magnitude results from the change in the maximum capacitance and the creation of an intermediate capacitance level $\left(\mathrm{C}_{\text {mid }}\right)$ when a Schottky barrier is present in the device (Figure 3(b)). In the absence of a Schottky barrier contact, the capacitance is equal to the junction capacitance $\left(C_{j}\right)$ for high frequencies and increases to the junction plus the trap state capacitance $\left(C_{j}+C_{t}\right)$ at low frequencies. In the presence of a Schottky barrier contact, it can be derived (see Appendix A) that the maximum capacitance is equivalent to 

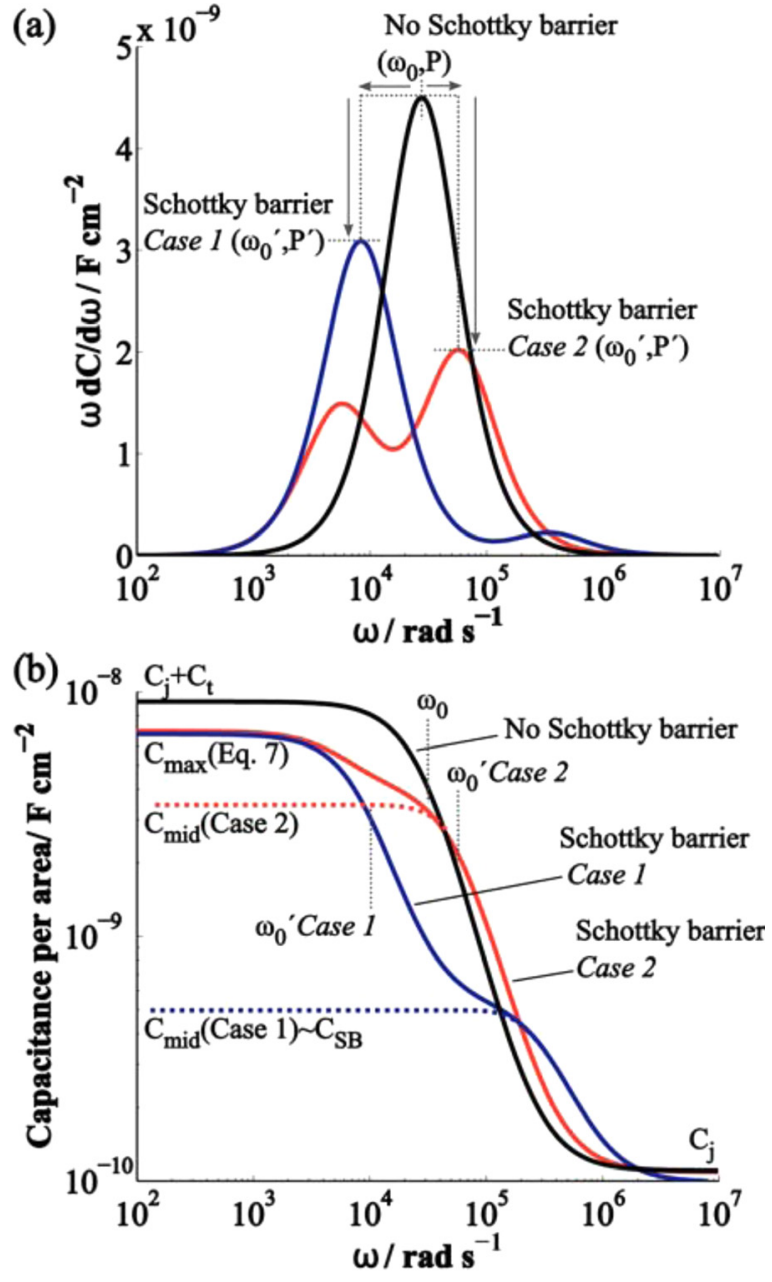

FIG. 3. (a) Modeled differential capacitance for a device with a trap state in the absence and presence of a Schottky barrier contact. In the absence of a Schottky barrier, the trap state peak magnitude and frequency exist at the location $\left(\omega_{0}, \mathrm{P}\right)$. In the presence of a Schottky barrier, the apparent trap state peak moves to a location $\left(\omega_{0}{ }^{\prime}, \mathrm{P}^{\prime}\right)$. (b) Capacitance versus frequency for the same devices modeled in (a).

$$
C_{\max }=\frac{C_{S B} R_{S B}^{2}+\left(C_{j}+C_{t}\right) R_{j}^{2}}{\left(R_{S B}+R_{j}\right)^{2}} .
$$

The differential capacitance corresponding to the apparent trap state in Case 1 will thus represent the change from $\mathrm{C}_{\text {mid }} \sim \mathrm{C}_{\mathrm{SB}}$ to $\mathrm{C}_{\max }$ (i.e., $\left.\omega \cdot \mathrm{dC} / \mathrm{d} \omega \sim \omega \cdot \Delta\left(\mathrm{C}_{\max }-\mathrm{C}_{\mathrm{SB}}\right) / \Delta \omega\right)$. Since $\mathrm{C}_{\mathrm{SB}}>\mathrm{C}_{\mathrm{j}}$ and $\mathrm{C}_{\max }<\mathrm{C}_{\mathrm{j}}+\mathrm{C}_{\mathrm{t}}$, the peak in the differential capacitance plot is lowered when a Schottky barrier is present in the device. The presence of $\mathrm{R}_{\mathrm{SB}}$ also pushes the peak to a lower frequency $\left(\omega_{0}^{\prime}<\omega_{0}\right)$. Larger values of $\mathrm{R}_{\mathrm{SB}}$ push $\omega_{0}^{\prime}$ further away from $\omega_{0}$. In the supplementary material, ${ }^{32}$ we present the percent error of the trap state peak magnitude and frequency as a function of each of the circuit model parameters.

Case $2\left(\mathrm{C}_{\mathrm{SB}}>\mathrm{C}_{\mathrm{t}}>\mathrm{C}_{\mathrm{j}}, \tau_{\mathrm{SB}}>\tau_{\mathrm{t}}>\tau_{\mathrm{j}}\right)$ exemplifies that the apparent trap state peak can also exist at a frequency greater than $\omega_{0}$ for a different set of capacitances and time constants. For this case, the differential capacitance will correspond to the change from the minimum capacitance $(\sim \mathrm{Cj})$ to $\mathrm{C}_{\text {mid }}$. Since $\mathrm{C}_{\text {mid }}<\mathrm{C}_{\mathrm{j}}+\mathrm{C}_{\mathrm{t}}, \mathrm{P}^{\prime}<\mathrm{P}$ similar to Case 1. Unlike Case $1, \mathrm{C}_{\mathrm{SB}}$ is more influential than $\mathrm{R}_{\mathrm{SB}}$ in Case 2 on the apparent trap state peak frequency $\left(\omega_{0}^{\prime}\right)$. Smaller values of $\mathrm{C}_{\mathrm{SB}}$ push $\omega_{0}{ }^{\prime}$ further from $\omega_{0}$. As we show in Secs. III C and IV, it is necessary to perform equivalent circuit analysis to identify the apparent trap state peak and separate the contributions of the different circuit elements.

\section{Modeled influence of a Schottky barrier contact on the density of states, capture cross section, and trap state energy}

In this section, we model the impact of the Schottky barrier on the measured trap state recombination parameters by considering how the temperature dependence of the Schottky barrier circuit elements alters the expected temperaturefrequency relationship (Eq. (1)) of the apparent trap state peak. We consider temperature dependent resistance $\left[R_{t}(T)\right.$, $\mathrm{R}_{\mathrm{SB}}(\mathrm{T})$, and $\mathrm{R}_{\mathrm{j}}(\mathrm{T})$ ] with either (1) temperature independent capacitance $\left[\mathrm{C}_{\mathrm{t}}, \mathrm{C}_{\mathrm{SB}}\right.$, and $\left.\mathrm{C}_{\mathrm{j}}\right]$ or (2) temperature dependent capacitance $\left[\mathrm{C}_{\mathrm{t}}(\mathrm{T}), \mathrm{C}_{\mathrm{SB}}(\mathrm{T})\right.$, and $\left.\mathrm{C}_{\mathrm{j}}(\mathrm{T})\right]$.

The temperature dependence of $\mathrm{R}_{t}$ can be defined by Eqs. (1), (8), and (9), which relates $R_{t}(T)$ to $\omega_{0}(T)$ and $C_{t}(T)$

$$
\begin{gathered}
\omega_{0}=\frac{1}{\tau_{t}}=\frac{1}{R_{t} C_{t}}, \\
R_{t}(T)=\left(C_{t}(T) \omega_{0}\right)^{-1}=\left(C_{t}(T) \xi_{0} T^{2} e^{-E_{0} / k T}\right)^{-1} .
\end{gathered}
$$

The occupancy of interface states is expected to be a function of the free carrier density at the interface, particularly that of the more highly doped side of the pn junction. For an $\mathrm{n}^{+}$-p junction, we consider $\mathrm{C}_{\mathrm{t}}(\mathrm{T}) \propto \mathrm{n}_{\mathrm{i}}(\mathrm{T})$ defined by ${ }^{33}$

$$
C_{t}(T) \propto n_{i}(T)=N_{C} e^{-E_{f n i} / k T}=A_{t} T^{1.5} e^{-E_{f n i} / k T},
$$

where $A_{t}$ is a temperature independent constant, $E_{f n i}$ is the interface Fermi level position in the n-material, and $\mathrm{N}_{\mathrm{C}}$ is effective density of states in the conduction band which has a temperature dependence ${ }^{33}$ of $\mathrm{T}^{1.5}$. Likewise, the temperature dependence of $\mathrm{C}_{\mathrm{SB}}(\mathrm{T})$ is related to the free carrier density of the bulk n-material, $\mathrm{N}_{\mathrm{D}}(\mathrm{T})$, by

$$
C_{S B}(T)=\frac{\varepsilon_{S B} A}{W_{S B}}=\sqrt{\frac{q \varepsilon_{S B} N_{D}(T) A^{2}}{2 \Phi_{S B}}}=A_{S B, C} \sqrt{T^{1.5} e^{-E_{f n \infty} / k T}} .
$$

The temperature independent pieces of the dielectric constant $\left(\varepsilon_{\mathrm{SB}}\right)$, depletion width $\left(\mathrm{W}_{\mathrm{SB}}\right)$, and barrier height $\left(\Phi_{\mathrm{SB}}\right)$ are summarized by $\mathrm{A}_{\mathrm{SB}, \mathrm{C}}$. $\mathrm{E}_{\mathrm{fn} \infty}$ is the bulk Fermi level position in the n-material and $\mathrm{A}$ is the area of the sample.

We assume that conduction over the Schottky barrier occurs via thermionic emission. ${ }^{33}$ Thus $\mathrm{R}_{\mathrm{SB}}(\mathrm{T})$ will behave in accordance with Eq. (12), ${ }^{12}$ with a constant $\mathrm{A}_{\mathrm{SB}, \mathrm{R}}$

$$
R_{S B}(T)=A_{S B, R} T^{-1} e^{\Phi_{S B} / k T}
$$

The temperature dependent junction capacitance (Eq. (13)) will behave in the same manner as $\mathrm{C}_{\mathrm{SB}}$ (Eq. (11)), but will be dependent on the p-material concentration, $\mathrm{N}_{\mathrm{A}}(\mathrm{T})$, with constant $\mathrm{A}_{\mathrm{SB}, \mathrm{j}}$ 

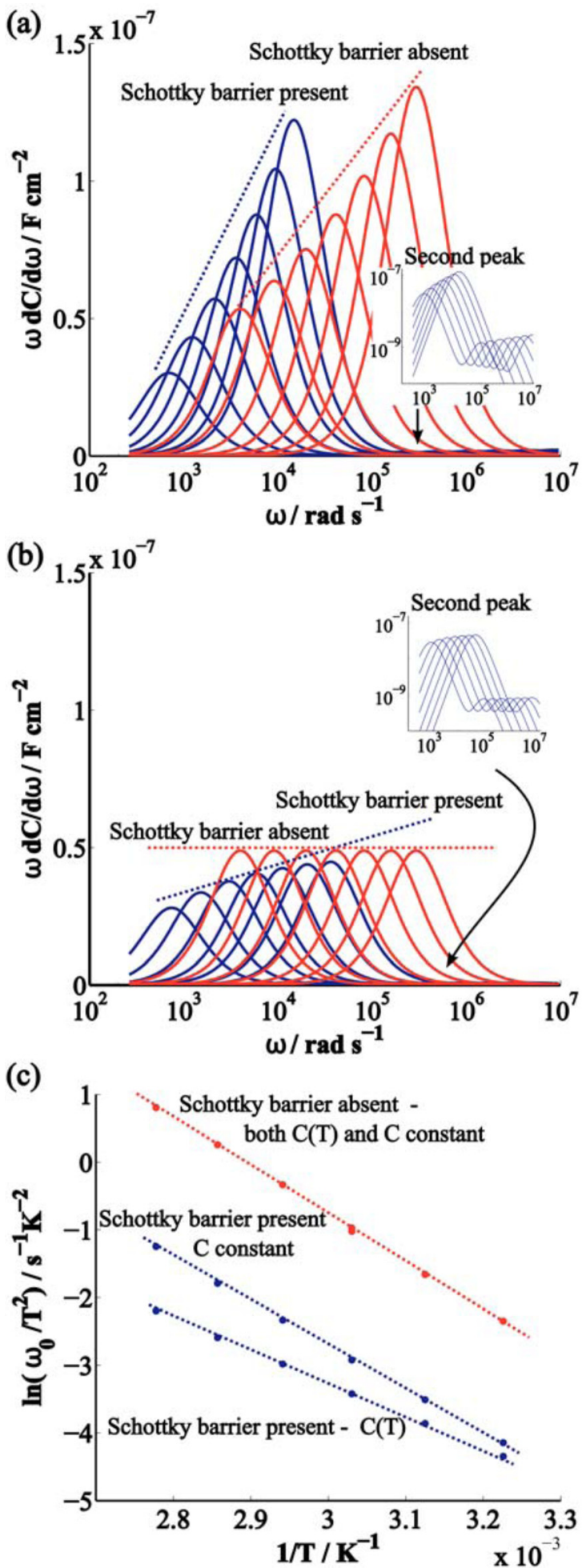

FIG. 4. Modeled differential capacitance plots of the equivalent circuit in Figure 2 considering (a) temperature dependent $\mathrm{C}_{t}, \mathrm{C}_{\mathrm{SB}}$, and $\mathrm{C}_{\mathrm{j}}$ and (b) temperature independent $C_{t}(T), C_{S B}(T)$, and $C_{j}(T)$. For both (a) and (b), the plots show the differential capacitance at different temperatures in the presence (blue) and absence (red) of the Schottky barrier. Arrhenius plots based on Eq. (1) of the four scenarios are given in (c). For the temperature independent scenarios, $\mathrm{C}_{\mathrm{t}}=9.8 \times 10^{-8} \mathrm{~F} \mathrm{~cm}^{-2}, \mathrm{C}_{\mathrm{SB}}=4.3 \times 10^{-9} \mathrm{~F} \mathrm{~cm}^{-2}$, $\mathrm{C}_{\mathrm{j}}=2.6 \times 10^{-6} \mathrm{~F} \mathrm{~cm}^{-2}$. Model parameters were used to give roughly equivalent capacitance and resistance values between the temperature independent and dependent scenarios at $300 \mathrm{~K}$. Model parameters are $\mathrm{A}_{\mathrm{t}, \mathrm{C}}=9.9 \times 10^{-10}$ $\mathrm{F} \mathrm{cm}^{-2} \mathrm{~K}^{-2}, \quad \mathrm{E}_{\mathrm{fpi}}=0.61 \mathrm{eV}, \quad \sigma_{\mathrm{C}}=6.3 \times 10^{-13} \mathrm{~cm}^{2}, \quad \mathrm{~A}_{\mathrm{SB}, \mathrm{C}}=4.3 \times 10^{-9}$ $\mathrm{F} \mathrm{cm}^{-2} \mathrm{~K}^{4 / 3}, \mathrm{E}_{\mathrm{fn} \infty}=0.1 \mathrm{eV}, \Phi_{\mathrm{SB}}=0.6 \mathrm{eV}, \mathrm{A}_{\mathrm{SB}, \mathrm{R}}=3.4 \times 10^{-4} \Omega \mathrm{cm}^{2} \mathrm{~K}$, $\mathrm{C}_{\mathrm{j}, \mathrm{C}}=1.4 \times 10^{-8} \mathrm{~F} \mathrm{~cm}^{-2} \mathrm{~K}^{4 / 3}, \mathrm{E}_{\mathrm{fp} \infty}=0.37 \mathrm{eV}, \mathrm{A}_{\mathrm{j}, \mathrm{R}}=1 \times 10^{-9} \Omega \mathrm{cm}^{2}$, $\mathrm{T}_{\mathrm{j}, \mathrm{R}}=30 \mathrm{~K}$.

$$
C_{j}(T)=\frac{\varepsilon_{j} A}{W_{j}}=\sqrt{\frac{q \varepsilon_{j} N_{A}(T) A^{2}}{2 \Phi_{j}}}=A_{S B, j} \sqrt{T^{1.5} e^{-E_{f p \infty} / k T}} .
$$

Lastly, $R_{j}(T)$ is defined by the following equation with constants $A_{j}$ and $T_{j}$ as has been observed elsewhere for polycrystalline semiconductors ${ }^{34}$

$$
R_{j}(T)=A_{j} e^{-T / T_{j}} .
$$

Figure 4 shows the differential capacitance calculated at different temperatures in the presence and absence of a Schottky barrier for the temperature dependent capacitance scenario (Figure 4(a)) and temperature independent capacitance scenario (Figure 4(b)). As for Figure 3, the presence of the Schottky barrier is seen to change the magnitude and frequency position of the apparent trap state peak at each temperature. The capture cross section $\left(\sigma_{\mathrm{C}}\right)$ and trap state energy $\left(E_{0}\right)$ were calculated from an Arrhenius plot of Eq. (1) for all four models (Figure 4(c)). The maximum density of trap states was also estimated from the peak value at $300 \mathrm{~K}$.

As shown in Table I, the model recombination parameters $\left(\mathrm{E}_{0}=\mathrm{E}_{\mathrm{fpi}}=0.61 \mathrm{eV}, \sigma_{\mathrm{C}}=6.3 \times 10^{-13} \mathrm{~cm}^{2}\right.$, and $\mathrm{N}_{\mathrm{t}}(300 \mathrm{~K})$ $=6.1 \times 10^{12} \mathrm{~cm}^{-2} \mathrm{eV}^{-1}$ ) were reproduced within $1 \%$ by the Arrhenius plot for both temperature independent and temperature dependent capacitance scenarios in the absence of the Schottky barrier. However, in the presence of the Schottky barrier, all three recombination parameters were vastly different from the input values. A reduction in the observed density of trap states resulted from the reduced peak magnitude $\left(\mathrm{P}^{\prime}<\mathrm{P}\right)$. The percent error was found to be similar for both scenarios $(\sim 50 \%)$.

The interface energy and capture cross section obtained from the apparent trap state peaks were also largely different from the input parameters. For temperature independent capacitances, the error in the trap state energy was $\sim 10 \%$ and capture cross section was $\sim 100 \%$. For temperature dependent capacitances, the error was much worse, reaching $\sim 32 \%$ in trap state energy $(0.41 \mathrm{eV}$ vs $0.61 \mathrm{eV}$ input $)$ and $\sim 4$-orders of magnitude difference $\left(5.6 \times 10^{-17} \mathrm{~cm}^{2}\right.$ vs $6.3 \times 10^{-13} \mathrm{~cm}^{2}$ input) in the capture cross section.

The error in both scenarios is largely due to the temperature dependence of $\mathrm{R}_{\mathrm{SB}}$. Since, the apparent trap state peak will be a mixture of contributions from the trap state and Schottky barrier, and since $\mathrm{R}_{\mathrm{SB}}$ (Eq. (12)) obeys a different temperature relationship than $R_{t}$ (Eq. (9)), the temperature dependence of the apparent peak frequency $\left(\omega_{0}{ }^{\prime}\right)$ and hence the recombination parameters obtained by fitting to an Arrhenius plot (Eq. (1)) will be different than in the absence of a Schottky barrier. When $\mathrm{C}_{\mathrm{SB}}(\mathrm{T})$ and $\mathrm{C}_{\mathrm{t}}(\mathrm{T})$ also have different temperature relationships, an Arrhenius plot of the apparent trap state peak frequency deviates even further from the appropriate correlation. Due to the expected temperature dependence of interface states (Eq. (10)), it is clear that the Schottky barrier contact contribution must be subtracted. Additionally, since the product of the recombination parameters can be used to estimate the dark saturation current (Eq. (4)), the error in measuring the recombination parameters can lead to a very inaccurate assessment of the device performance. 
TABLE I. Comparison of the trap state energy $\left(\mathrm{E}_{0}\right)$, capture cross section $\left(\sigma_{\mathrm{C}}\right)$, and density of states $\left(\mathrm{N}_{\mathrm{t}}\right)$ for different models considering temperature independent and dependent capacitance in the presence and absence of a Schottky barrier contact.

\begin{tabular}{lccc}
\hline \hline & $\begin{array}{c}\mathrm{E}_{0} \\
(\mathrm{eV})\end{array}$ & $\begin{array}{c}\sigma_{\mathrm{C}} \\
\left(\mathrm{cm}^{2}\right)\end{array}$ & $\begin{array}{c}\mathrm{N}_{\mathrm{t}} \text { at } 300 \mathrm{~K} \\
\left(\mathrm{~cm}^{-2} \mathrm{eV}^{-1}\right)\end{array}$
\end{tabular}

Temperature independent capacitance

Schottky barrier absent

Schottky barrier present

0.61

0.61

0.55

$6.3 \times 10^{-13}$

$6.1 \times 10^{12}$

$6.3 \times 10^{-13}$

$6.1 \times 10^{12}$

$3.5 \times 10^{12}$

Temperature dependent capacitance

Input

Schottky barrier absent

Schottky barrier present

\begin{tabular}{lll}
0.61 & $6.3 \times 10^{-13}$ & $6.6 \times 10^{12}$ \\
0.61 & $6.3 \times 10^{-13}$ & $6.6 \times 10^{12}$ \\
0.41 & $5.6 \times 10^{-17}$ & $3.9 \times 10^{12}$ \\
\hline
\end{tabular}

IV. TEST CASE: USING EQUIVALENT CIRCUIT MODELING WITH ADMITTANCE SPECTROSCOPY TO MEASURE INTERFACE STATE PARAMETERS IN A SOLUTION PROCESSED $\mathrm{ZnO} / \mathrm{Cu}_{2} \mathrm{O}$ DEVICE IN THE PRESENCE OF AN ITO/ZnO SCHOTTKY BARRIER

In this section, we use equivalent circuit modeling to eliminate the effects of an ITO/ZnO Schottky barrier for analyzing interface state properties in a $\mathrm{ZnO} / \mathrm{Cu}_{2} \mathrm{O}$ device measured by admittance spectroscopy. The density and capture cross section of any trap state are important parameters that will allow more accurate modeling of the device response in the future using simulation programs such as SCAPS. ${ }^{35}$

Three equivalent circuit models (Figures 5(a)-5(c)) were fit to the raw admittance data using the LEVMw nonlinear least squares regression fitting software. ${ }^{17}$ As noted in $\mathrm{Sec}$. II, the $\mathrm{ZnO}$ carrier density is multiple orders of magnitude greater than the $\mathrm{Cu}_{2} \mathrm{O}$ carrier density. Thus, the n-region capacitance was neglected from the models for equivalent circuit analysis. Figure 5(a) shows a simple circuit model similar to Figure 2 with additional series resistance $\left(\mathrm{R}_{\mathrm{S}}\right)$ due to conduction through the neutral semiconductor regions and inductance $(\mathrm{L})$ of the wires between the instrument and the device. The simple model, however, was found to be a poor representation of the experimental data with up to a $25 \%$ error (Figure 5(d)) for some frequencies.

While the ultimate goal for photovoltaics is lowtemperature, scalable growth such as by solution deposition, semiconductors produced by solution deposited techniques are known to be inhomogeneous due to the polycrystalline growth $^{21,36}$ and large concentration of hydroxyl groups ${ }^{28,36}$ that can become trapped in the films. The constant phase element (CPE) is a versatile distributed element that has previously been used by our group to describe the inhomogenities in the $\mathrm{ZnO}$ film of the ITO/ZnO Schottky barrier. ${ }^{1}$ The impedance of the CPE is given by Eq. (15), ${ }^{17}$

$$
Z_{C P E}=\frac{1}{Q(j \omega)^{n}}=\left(Q \omega^{n}\left[\cos \left(\frac{\pi n}{2}\right)+j \sin \left(\frac{\pi n}{2}\right)\right]\right)^{-1} .
$$

In this equation, $\mathrm{n}$ is an ideality factor with values between 0 and 1 . For $\mathrm{n}=1$, the CPE represents a pure capacitance with $\mathrm{Q}=\mathrm{C}$. For $\mathrm{n}=0$, the $\mathrm{CPE}$ is a pure resistor with $\mathrm{Q}=1 / \mathrm{R}$.
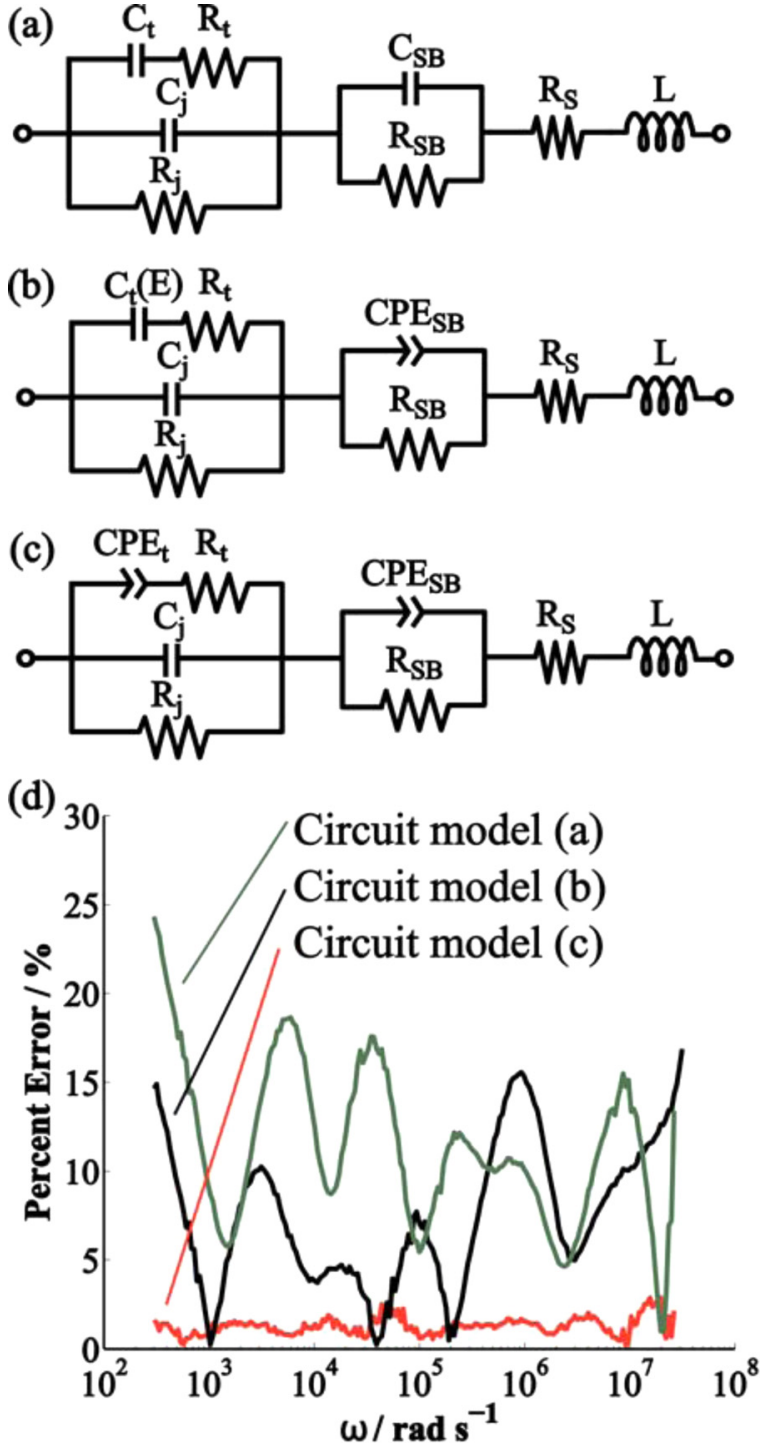

FIG. 5. (a)-(c) Equivalent circuit models and (d) percent error (100\%* IModel - Datal/Data) of the magnitude of admittance versus frequency at $300 \mathrm{~K}$. Circuit model (a) uses a pure capacitor for $\mathrm{C}_{\mathrm{t}}$ and $\mathrm{C}_{\mathrm{SB}}$. Circuit model (b) uses a CPE to replace $\mathrm{C}_{\mathrm{SB}}$ and a Gaussian distribution of states for $\mathrm{C}_{\mathrm{t}}$. Circuit model (c) uses a CPE for $\mathrm{C}_{\mathrm{t}}$ and $\mathrm{C}_{\mathrm{SB}}$.

Lateral inhomogeneity at the pn junction interface is also expected to exist in solution deposited samples. ${ }^{1}$ Other researchers ${ }^{2,37,38}$ have discussed the influence of lateral inhomogeneity on the device electric behavior and have suggested using a Gaussian function ${ }^{2,37}$ to represent a broad distribution of band levels that can exist at the interface. We find that the $\mathrm{CPE}$ can also describe the interface energy variability. Good fits ( $<3 \%$ error for all frequencies) were obtained for the electrodeposited $\mathrm{ZnO} / \mathrm{Cu}_{2} \mathrm{O}$ system when using the CPE (Figure 5(d)).

Admittance data modeled using the equivalent circuit in Figure 5(c) were found to accurately reproduce the raw data for all temperatures (Figure 6). The resulting fit parameters and error are given in Appendix B. It is noted that a junction capacitance of $\sim 4 \times 10^{-9} \mathrm{~F} \mathrm{~cm}^{-2}$ was obtained which gives a depletion width of $1.6 \mu \mathrm{m}$ and matches well with the expected depletion width $(1.5-3 \mu \mathrm{m})$ based on the carrier densities of the $\mathrm{ZnO}$ and $\mathrm{Cu}_{2} \mathrm{O}$ layers (Sec. II). The Schottky 


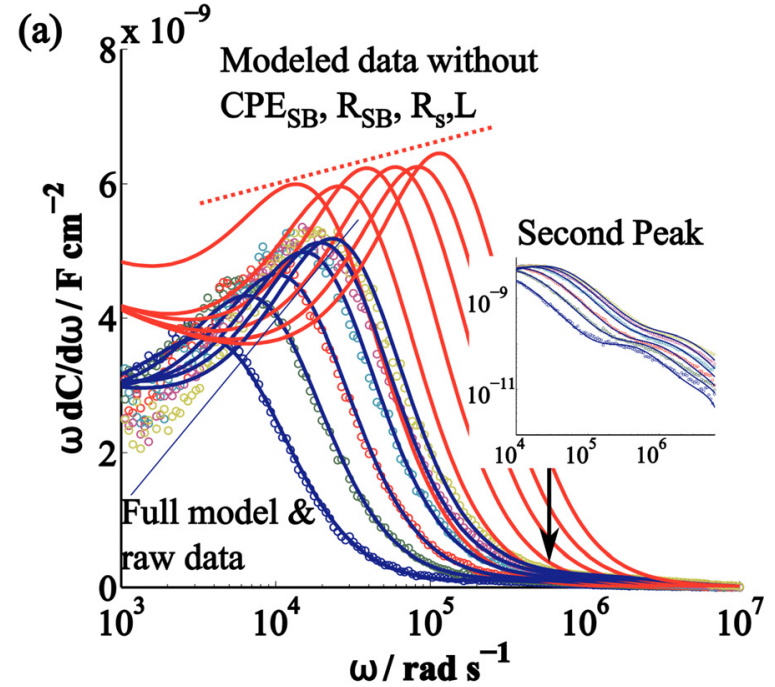

(b)

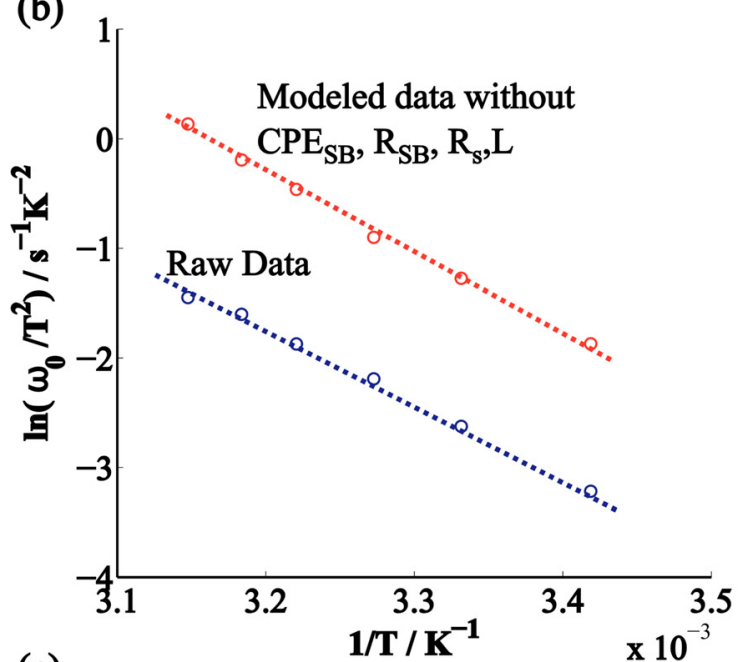

(c)

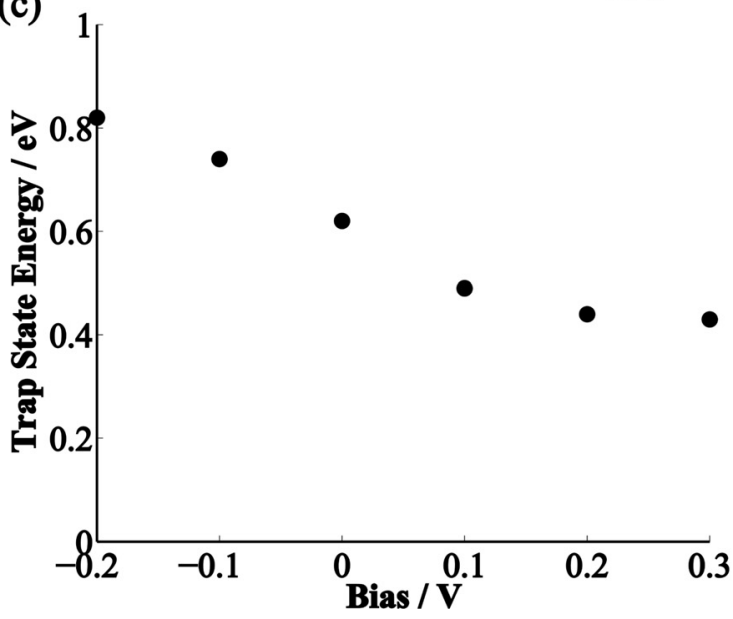

FIG. 6. (a) Admittance spectroscopy data of a $\mathrm{ZnO} / \mathrm{Cu}_{2} \mathrm{O}$ device with an ITO/ZnO Schottky barrier measured from 290-320 K (open circles). The full modeled data (blue lines) and modeled data without $\mathrm{CPE}_{\mathrm{SB}}, \mathrm{R}_{\mathrm{SB}}, \mathrm{R}_{\mathrm{S}}$, and $\mathrm{L}$ (red lines) are also presented. (b) Arrhenius plot of the trap state peak of the raw data (blue) and modeled data with the Schottky barrier, series resistance, or inductance contributions (red). (c) Correlation of the interface trap state energy with bias.

barrier, series resistance, and inductance were then subtracted so that only the pn junction and trap state contributions remained. The differential capacitance of the pn junction and trap state components (calculated from Eqs.
(A1)-(A4)) at each temperature was calculated and re-plotted alongside the original data in Figure 6(a).

From an Arrhenius plot of Eq. (1) (Figure 6(b)), the energy and capture cross section were calculated from the trap state peak with and without equivalent circuit modeling. In addition, Figure 6(c) shows that the trap state energy is bias dependent, thus confirming that this trap state arises from a continuous distribution of trap states located at the pn junction interface as explained earlier in this work. The density of interface states was also estimated using Eq. (3) from the peak magnitude of the differential capacitance plots with and without equivalent circuit analysis. These results are presented in Table II.

Table II shows that the apparent density of interfacial trap states measured in the presence of the ITO/ZnO contact is $\sim 30 \%$ lower than the value measured after equivalent circuit modeling. Likewise, the interface Fermi level position and capture cross section are also lower than the true value by $\sim 10 \%(0.55 \mathrm{eV}$ raw vs $0.62 \mathrm{eV}$ model) and $\sim 40$-times $\left(1.2 \times 10^{-13} \mathrm{~cm}^{2}\right.$ raw vs $4.5 \times 10^{-12} \mathrm{~cm}^{2}$ model $)$, respectively. These results are consistent with the theory presented in Secs. III A-III C. The temperature dependence of $\mathrm{R}_{\mathrm{SB}}$ and $\mathrm{C}_{\mathrm{SB}}$ changes the apparent trap state peak's expected temperature-frequency relationship (Eq. (1)) and produces an error in the measured recombination parameters.

Using Eq. (5), the interface recombination velocity (S) was calculated to be $\sim 7 \times 10^{5} \mathrm{~cm} \mathrm{~s}^{-1}$. This recombination velocity is relatively high compared to other photovoltaic devices. Typically, vacuum-fabricated devices (such as in c$\mathrm{Si}$ or GaAs-based devices) have recombination velocities below $10^{5} \mathrm{~cm} \mathrm{~s}^{-1}$ with some reaching values on the order of $10^{0} \mathrm{~cm} \mathrm{~s}^{-1}$ when passivation techniques are employed. ${ }^{39,40}$

Recombination velocity is proportional to the product of density of trap states and the capture cross section (Eq. (5)). Generally, the density of trap states and capture cross section have values between $10^{10}-10^{13} \mathrm{~cm}^{-2} \mathrm{eV}^{-1}$ (density of states) and $10^{-20}-10^{-14} \mathrm{~cm}^{2}$ (capture cross section). ${ }^{41,42}$ As shown in Table II, the capture cross section is very large $\left(>1 \times 10^{-13} \mathrm{~cm}^{2}\right)$ for $\mathrm{ZnO} / \mathrm{Cu}_{2} \mathrm{O}$ and is the dominant contributor to the recombination velocity.

While it is unknown at this time what causes the large capture cross section, we speculate that this could arise from (1) clustering of trap states or (2) a low electric field at the pn junction interface. The capture cross section describes the area of influence of a trap state. If a free carrier passes through this area, the carrier can be coulombically attracted towards the charged trap and recombine. Clustered traps can act collectively, expressing a larger area of influence than an independent trap site. Due to the high defect concentrations present in $\mathrm{ZnO}^{43}$ and $\mathrm{Cu}_{2} \mathrm{O},{ }^{44,45}$ it is reasonable to expect defects to migrate and cluster at the interface.

Capture cross section also describes the propensity of a free carrier's path to be influenced. A free carrier's path is less likely to be diverted when moving with a high velocity in the presence of an electric field. Due to the low free carrier density in $\mathrm{Cu}_{2} \mathrm{O}\left(\sim 1 \times 10^{14} \mathrm{~cm}^{-3}\right),{ }^{21,46}$ a low electric field $\left(\sim 10^{3} \mathrm{~V} \mathrm{~cm}^{-1}\right)$ is expected at the interface.

Lastly, it is noted that other trap states may exist. Due to the compensated nature of $\mathrm{Cu}_{2} \mathrm{O}$, ionized deep donor states 
TABLE II. Summarized admittance spectroscopy results averaged ( \pm 1 standard deviation) for $3 \mathrm{ZnO} / \mathrm{Cu}_{2} \mathrm{O}$ devices. Raw data include an ITO/ZnO Schottky barrier. Modeled data subtract the Schottky barrier contact as well as the additional series resistance and inductance.

\begin{tabular}{lccr}
\hline \hline & $\mathrm{E}_{\mathrm{fpi}}(\mathrm{eV})$ & $\sigma_{\mathrm{C}}\left(\mathrm{cm}^{2}\right)$ & $\mathrm{Max} \mathrm{N}_{\mathrm{t}}$ at $300 \mathrm{~K}\left(\mathrm{~cm}^{-2} \mathrm{eV}^{-1}\right)$ \\
\hline Raw data & $0.55 \pm 0.03$ & $1.2 \times 10^{-13} \pm 1.0 \times 10^{-13}$ & $1.8 \times 10^{11} \pm 4.5 \times 10^{10}$ \\
Modeled data $\left(\mathrm{R}_{\mathrm{SB}}, \mathrm{CPE}_{\mathrm{SB}}, \mathrm{R}_{\mathrm{S}}, \mathrm{L}\right.$ subtracted) & $0.62 \pm 0.02$ & $4.5 \times 10^{-12} \pm 3.2 \times 10^{-12}$ & $2.6 \times 10^{11} \pm 7.4 \times 10^{10}$ \\
\hline \hline
\end{tabular}

can accept electrons and act as recombination centers. ${ }^{44,45}$ However, it is apparent from the voltage dependence of the trap state energy (Figure 6(c)) that interface states are the dominant trap location in a fully electrodeposited $\mathrm{ZnO} / \mathrm{Cu}_{2} \mathrm{O}$ device.

\section{CONCLUSIONS}

Equivalent circuit analysis was shown to be an imperative supplement to admittance spectroscopy when analyzing recombination parameters of interface states in a pn junction solar cell containing a Schottky barrier contact. Both interface states and a Schottky barrier contact produced a response in the admittance data. Without equivalent circuit modeling, the temperature dependence of the Schottky barrier resistance and capacitance forced the apparent trap state response to deviate from its true frequency-temperature relationship. Modeling showed that this deviation could produce $\sim 4$-orders of magnitude error in the measured capture cross section. By applying equivalent circuit modeling to a fully electrodeposited $\mathrm{ZnO} / \mathrm{Cu}_{2} \mathrm{O}$ device containing an ITO/ZnO Schottky barrier, we accurately determined the interface trap state recombination parameters and recombination velocity $\left(\sim 7 \times 10^{5} \mathrm{~cm} \mathrm{~s}^{-1}\right)$. The high recombination velocity, as expected for a solution deposited device, was mainly attributed to very large capture cross section $\left(\sim 5 \times 10^{-12} \mathrm{~cm}^{2}\right)$.

\section{ACKNOWLEDGMENTS}

The authors would like to acknowledge the International Copper Association, the ERC for the Advanced Investigator Grant, Novox, ERC-2009-adG 247276, the Gates Cambridge Trust, and Girton College (Cambridge) for funding this work.

\section{APPENDIX A: SOLVING FOR THE MAXIMUM CAPACITANCE}

Admittance spectroscopy relies on Eqs. (A1) and (A2) which define the admittance for a pn junction with a trap state

$$
Y_{p n}=\frac{1}{Z_{p n}}=\frac{1}{R_{t}+\left(j \omega C_{t}\right)^{-1}}+\frac{1}{R_{j}}+j \omega C_{j}
$$

$$
Y_{p n}=G_{p n}+j B_{p n}=\frac{1}{R_{j}}+\frac{\omega^{2} \tau_{t} C_{t}}{\omega^{2} \tau_{t}^{2}+1}+j\left[\omega C_{j}+\frac{\omega C_{t}}{\omega^{2} \tau_{t}^{2}+1}\right]
$$

where $\tau_{\mathrm{t}}=\mathrm{R}_{\mathrm{t}} \mathrm{C}_{\mathrm{t}}$. The junction capacitance will be the suscepectance (B) divided by the frequency, given by

$$
C_{p n}=B_{p n} / \omega=C_{j}+\frac{C_{t}}{\omega^{2} \tau_{t}^{2}+1} .
$$

Taking the derivative of this equation and multiplying by $\omega$ results in Eq. (A4) which gives the differential capacitance of a junction with a trap state. It can be shown that at $\omega_{0}=1 / \tau_{\mathrm{t}}$ $\left(\omega_{0}\right.$ defined by Eq. (1)) the peak of the differential capacitance will be equal to $\mathrm{C}_{\mathrm{t}} / 2$ (Eq. (3))

$$
\omega \frac{d C_{p n}}{d \omega}=\omega \frac{2 C_{t} \omega \tau_{t}^{2}}{\left(\omega^{2} \tau_{t}^{2}+1\right)^{2}} .
$$

The total capacitance changes if a Schottky barrier is present in the device according to the following equations:

$$
\begin{gathered}
Z_{\text {Total }}=Z_{S B}+Z_{p n}, \\
Y_{S B}=\frac{1}{Z_{S B}}=\frac{1}{R_{S B}}+j \omega C_{S B}, \\
Z_{S B}=\frac{R_{S B}}{1+\omega^{2} \tau_{S B}{ }^{2}}-j \frac{\omega \tau_{S B} R_{S B}}{1+\omega^{2} \tau_{S B}{ }^{2}}, \\
Z_{\text {total }}=\frac{R_{S B}}{1+\omega^{2} \tau_{S B}{ }^{2}}-j \frac{\omega \tau_{S B} R_{S B}}{1+\omega^{2} \tau_{S B}{ }^{2}}+\frac{G_{p n}}{G_{p n}{ }^{2}+B_{p n}{ }^{2}} \\
-j \frac{B_{p n}}{G_{p n}{ }^{2}+B_{p n}{ }^{2}}, \\
Y_{\text {total }}=\frac{1}{Z_{\text {total }}}=G_{\text {total }}+j B_{\text {total }},
\end{gathered}
$$

and

$$
C_{\text {total }}=B_{\text {total }} / \omega=\frac{\frac{\tau_{S B} R_{S B}}{1+\omega^{2} \tau_{S B}^{2}}+\frac{C_{p n}}{G_{p n}^{2}+B_{p n}^{2}}}{\left(\frac{R_{S B}}{1+\omega^{2} \tau_{S B}{ }^{2}}+\frac{G_{p n}}{G_{p n}{ }^{2}+B_{p n}{ }^{2}}\right)^{2}+\left(\frac{\omega \tau_{S B} R_{S B}}{1+\omega^{2} \tau_{S B}{ }^{2}}+\frac{B_{p n}}{G_{p n}{ }^{2}+B_{p n}{ }^{2}}\right)^{2}} .
$$

The limit of Eq. (A10) can then be taken as $\omega \rightarrow 0$ in order to find the maximum capacitance $\left(\mathrm{C}_{\max }\right.$ in Eq. (4)) 


$$
\begin{gathered}
\lim _{\omega \rightarrow 0} C_{p n}=C_{j}+C_{t}, \\
\lim _{\omega \rightarrow 0} G_{p n}=\frac{1}{R_{j}}, \\
\lim _{\omega \rightarrow 0} B_{p n}=0,
\end{gathered}
$$

thus

$$
C_{\max }=\lim _{\omega \rightarrow 0} C_{\text {total }}=\frac{\tau_{S B} R_{S B}+\left(C_{j}+C_{t}\right) R_{j}^{2}}{\left(R_{S B}+R_{j}\right)^{2}} .
$$

\section{APPENDIX B: ECM FIT PARAMETERS FOR $\mathrm{ZnO} / \mathrm{Cu}_{2} \mathrm{O}$}

Tables III and IV present the circuit model parameters and standard deviation for fits of the admittance data for a $\mathrm{ZnO} / \mathrm{Cu}_{2} \mathrm{O}$ device.

TABLE III. Resulting circuit model fit parameters (using the model in Figure 4(c)) of data for a $\mathrm{ZnO} / \mathrm{Cu}_{2} \mathrm{O}$ device for different measurement temperatures. Fit parameters were obtained using the LEVMw nonlinear linear least squares regression fitting software. ${ }^{17}$ The resulting differential capacitance using these parameters is laid over the data in Figure 5(a). Q and $\mathrm{n}$ are components of the CPE from Eq. (15). The device area was $0.15 \mathrm{~cm}^{2}$.

\begin{tabular}{cccccc}
\hline \hline $\mathrm{T} / \mathrm{K}$ & $\mathrm{R}_{\mathrm{t}} / \Omega$ & $\mathrm{Q}_{\mathrm{t}}$ & $\mathrm{n}_{\mathrm{t}}$ & $\mathrm{R}_{\mathrm{j}} / \Omega$ & $\mathrm{C}_{\mathrm{j}} / \mathrm{F}$ \\
\hline 292 & $2.7 \times 10^{3}$ & $8.2 \times 10^{-8}$ & 0.83 & $1.8 \times 10^{4}$ & $5.9 \times 10^{-10}$ \\
300 & $1.6 \times 10^{3}$ & $7.4 \times 10^{-8}$ & 0.84 & $1.5 \times 10^{4}$ & $6.1 \times 10^{-10}$ \\
305 & $1.1 \times 10^{3}$ & $7.6 \times 10^{-8}$ & 0.85 & $1.0 \times 10^{4}$ & $6.2 \times 10^{-10}$ \\
310 & $7.3 \times 10^{2}$ & $7.6 \times 10^{-8}$ & 0.86 & $8.1 \times 10^{3}$ & $6.3 \times 10^{-10}$ \\
314 & $5.3 \times 10^{2}$ & $7.7 \times 10^{-8}$ & 0.86 & $6.9 \times 10^{3}$ & $6.5 \times 10^{-10}$ \\
318 & $3.8 \times 10^{2}$ & $7.8 \times 10^{-8}$ & 0.86 & $5.6 \times 10^{3}$ & $6.9 \times 10^{-10}$ \\
$\mathrm{~T} / \mathrm{K}$ & $\mathrm{R}_{\mathrm{SB}} / \Omega$ & $\mathrm{Q}_{\mathrm{SB}}$ & $\mathrm{n}_{\mathrm{SB}}$ & $\mathrm{R}_{\mathrm{s}} / \Omega$ & $\mathrm{L} / \mathrm{H}$ \\
\hline 292 & $7.8 \times 10^{3}$ & $2.0 \times 10^{-9}$ & 0.92 & $1.6 \times 10^{-8}$ & $1.0 \times 10^{-6}$ \\
300 & $4.4 \times 10^{3}$ & $2.9 \times 10^{-9}$ & 0.90 & $1.6 \times 10^{-8}$ & $1.0 \times 10^{-6}$ \\
305 & $2.8 \times 10^{3}$ & $3.7 \times 10^{-9}$ & 0.89 & $1.6 \times 10^{-8}$ & $9.9 \times 10^{-7}$ \\
310 & $1.9 \times 10^{3}$ & $5.6 \times 10^{-9}$ & 0.87 & $1.6 \times 10^{-8}$ & $9.8 \times 10^{-7}$ \\
314 & $1.5 \times 10^{3}$ & $8.0 \times 10^{-9}$ & 0.85 & $1.6 \times 10^{-8}$ & $9.7 \times 10^{-7}$ \\
318 & $1.3 \times 10^{3}$ & $9.9 \times 10^{-9}$ & 0.84 & $1.6 \times 10^{-8}$ & $9.6 \times 10^{-7}$ \\
\hline \hline
\end{tabular}

TABLE IV. Standard deviation of the circuit model fit parameters (Table III) reported by the LEVMw fitting software. $\mathrm{Q}$ and $\mathrm{n}$ are components of the CPE from Eq. (15). The device area was $0.15 \mathrm{~cm}^{2}$.

\begin{tabular}{cccccc}
\hline \hline $\mathrm{T} / \mathrm{K}$ & $\mathrm{R}_{\mathrm{t}} / \Omega$ & $\mathrm{Q}_{\mathrm{t}}$ & $\mathrm{n}_{\mathrm{t}}$ & $\mathrm{R}_{\mathrm{j}} / \Omega$ & $\mathrm{C}_{\mathrm{j}} / \mathrm{F}$ \\
\hline 292 & 45.3 & $1.2 \times 10^{-9}$ & $2.1 \times 10^{-3}$ & 40.4 & $4.6 \times 10^{-12}$ \\
300 & 21.8 & $7.3 \times 10^{-10}$ & $1.3 \times 10^{-3}$ & 20.4 & $4.0 \times 10^{-12}$ \\
305 & 13.8 & $6.0 \times 10^{-10}$ & $9.6 \times 10^{-4}$ & 11.9 & $4.0 \times 10^{-12}$ \\
310 & 9.9 & $6.0 \times 10^{-10}$ & $9.5 \times 10^{-4}$ & 9.24 & $4.4 \times 10^{-12}$ \\
314 & 7.3 & $6.6 \times 10^{-10}$ & $1.0 \times 10^{-3}$ & 8.18 & $4.7 \times 10^{-12}$ \\
318 & 4.9 & $6.7 \times 10^{-10}$ & $1.0 \times 10^{-3}$ & 6.63 & $5.2 \times 10^{-12}$ \\
$\mathrm{~T} / \mathrm{K}$ & $\mathrm{R}_{\mathrm{SB}} / \Omega$ & $\mathrm{Q}_{\mathrm{SB}}$ & $\mathrm{n}_{\mathrm{SB}}$ & $\mathrm{R}_{\mathrm{s}} / \Omega$ & $\mathrm{L} / \mathrm{H}$ \\
\hline 292 & 32.6 & $1.6 \times 10^{-9}$ & $6.8 \times 10^{-4}$ & $9.3 \times 10^{-3}$ & $1.3 \times 10^{-8}$ \\
300 & 15.7 & $1.8 \times 10^{-9}$ & $7.4 \times 10^{-4}$ & $9.3 \times 10^{-3}$ & $1.5 \times 10^{-8}$ \\
305 & 9.5 & $1.8 \times 10^{-9}$ & $8.3 \times 10^{-4}$ & $9.3 \times 10^{-3}$ & $2.1 \times 10^{-8}$ \\
310 & 6.8 & $2.2 \times 10^{-9}$ & $1.6 \times 10^{-3}$ & $9.3 \times 10^{-3}$ & $2.2 \times 10^{-8}$ \\
314 & 5.3 & $2.9 \times 10^{-9}$ & $1.4 \times 10^{-3}$ & $9.3 \times 10^{-3}$ & $2.0 \times 10^{-8}$ \\
318 & 4.1 & $3.2 \times 10^{-9}$ & $1.5 \times 10^{-3}$ & $9.3 \times 10^{-3}$ & $1.8 \times 10^{-8}$ \\
\hline \hline
\end{tabular}

${ }^{1}$ K. P. Musselman, A. Marin, A. Wisnet, C. Scheu, J. L. MacManusDriscoll, and L. Schmidt-Mende, Adv. Funct. Mater. 21, 573 (2011).

${ }^{2}$ R. Scheer, J. Appl. Phys. 105, 104505 (2009).

${ }^{3}$ H. Wilhelm, H. W. Schock, and R. Scheer, J. Appl. Phys. 109, 084514 (2011).

${ }^{4}$ R. Herberholz, M. Igalson, and H. W. Schock, J. Appl. Phys. 83, 318 (1998).

${ }^{5}$ A. Darga, Z. Djebbour, D. Mencaraglia, A. Migan Dubois, J. P. Connolly, J. F. Guillemoles, and D. Lincot, Phys. Status Solidi C 5, 3449 (2008).

${ }^{6}$ W. A. Strifler and C. W. Bates, J. Appl. Phys. 71, 4358 (1992).

${ }^{7}$ T. Walter, R. Herberholz, C. Müller, and H. W. Schock, J. Appl. Phys. 80, 4411 (1996).

${ }^{8}$ M. Burgelman and P. Nollet, Solid State Ionics 176, 2171 (2005).

${ }^{9}$ W. A. Hill and C. C. Coleman, Solid-State Electron. 23, 987 (1980).

${ }^{10}$ J. V. Li, X. Li, Y. Yan, C. S. Jiang, W. K. Metzger, I. L. Repins, M. A. Contreras, and D. H. Levi, J. Vac. Sci. Technol. B 27, 2384 (2009).

${ }^{11}$ T. Eisenbarth, T. Unold, R. Caballero, C. A. Kaufmann, and H. W. Schock, J. Appl. Phys. 107, 034509 (2010).

${ }^{12}$ J. V. Li, S. W. Johnston, X. Li, D. S. Albin, T. A. Gessert, and D. H. Levi, J. Appl. Phys. 108, 064501 (2010).

${ }^{13}$ S. Rühle and D. Cahen, J. Phys. Chem. B 108, 17946 (2004).

${ }^{14}$ D. C. Iza, D. Muñoz-Rojas, Q. Jia, B. Swartzentruber, and J. L. MacManus-Driscoll, Nanoscale Res. Lett. 7, 655 (2012).

${ }^{15}$ K. L. Chopra, P. D. Paulson, and V. Dutta, Prog. Photovoltaics 12, 69 (2004).

${ }^{16}$ J. Tang and E. H. Sargent, Adv. Mater. 23, 12 (2011).

${ }^{17}$ J. R. M. E. Barsoukov and J. R. Macdonald, Impedance Spectroscopy: Theory, Experiment, and Applications, 2nd ed. (Wiley \& Sons, Inc., Hoboken, NJ, 2005), p. 34.

${ }^{18}$ Y. Y. Proskuryakov, K. Durose, B. M. Taele, and S. Oelting, J. Appl. Phys. 102, 024504 (2007).

${ }^{19}$ J. Katayama, K. Ito, M. Matsuoka, and J. Tamaki, J. Appl. Electrochem. 34, 687 (2004).

${ }^{20}$ M. Izaki, T. Shinagawa, K. T. Mizuno, Y. Ida, M. Inaba, and A. Tasaka, J. Phys. D: Appl. Phys. 40, 3326 (2007).

${ }^{21}$ K. P. Musselman, A. Marin, L. Schmidt-Mende, and J. L. MacManusDriscoll, Adv. Funct. Mater. 22, 2202 (2012).

${ }^{22}$ T. Minami, Y. Nishi, T. Miyata, and J. Nomoto, Appl. Phys. Express 4, 062301 (2011).

${ }^{23}$ K. P. Musselman, T. Gershon, L. Schmidt-Mende, and J. L. MacManusDriscoll, Electrochim. Acta 56, 3758 (2011).

${ }^{24}$ S. Jeong, S. H. Song, K. Nagaich, S. A. Campbell, and E. S. Aydil, Thin Solid Films 519, 6613 (2011).

${ }^{25}$ A. Mittiga, E. Salza, F. Sarto, M. Tucci, and R. Vasanthi, Appl. Phys. Lett. 88, 163502 (2006).

${ }^{26}$ Y. Nishi, T. Miyata, and T. Minami, J. Vac. Sci. Technol. A 30, 04D103 (2012).

${ }^{27}$ W. G. Oldham and A. G. Milnes, Solid-State Electron. 7, 153 (1964).

${ }^{28}$ M. Izaki and T. Omi, Appl. Phys. Lett. 68, 2439 (1996).

${ }^{29}$ J. T. Heath, J. D. Cohen, and W. N. Shafarman, J. Appl. Phys. 95, 1000 (2004)

${ }^{30}$ J. Kneisel, K. Siemer, I. Luck, and D. Bräunig, J. Appl. Phys. 88, 5474 (2000).

${ }^{31}$ A. Niemegeers and M. Burgelman, J. Appl. Phys. 81, 2881 (1997).

${ }^{32}$ See supplementary material at http://dx.doi.org/10.1063/1.4799633 for apparent trap state percent error.

${ }^{33}$ S. M. Sze, Physics of Semiconductor Devices, 3rd ed. (John Wiley \& Sons, New York, 1981), p. 79.

${ }^{34}$ P. A. Fernandes, A. F. Sartori, P. M. P. Salomé, J. Malaquias, A. F. da Cunha, M. P. F. Graça, and J. C. González, Appl. Phys. Lett. 100, 233504 (2012).

${ }^{35}$ M. Burgelman, P. Nollet, and S. Degrave, Thin Solid Films 361-362, 527 (2000).

${ }^{36}$ B. N. Illy, A. C. Cruickshank, S. Schumann, R. D. Campo, T. S. Jones, S. Heutz, M. A. McLachlan, D. W. McComb, D. J. Riley, and M. P. Ryan, J. Mater. Chem. 21, 12949 (2011).

${ }^{37}$ J. H. Werner and H. H. Güttler, J. Appl. Phys. 69, 1522 (1991).

${ }^{38}$ U. Rau and J. H. Werner, Appl. Phys. Lett. 84, 3735 (2004).

${ }^{39}$ J. Han, P. Q. Mantas, and A. M. R. Senos, J. Eur. Ceram. Soc. 22, 49 (2002).

${ }^{40}$ B. Hoex, S. B. S. Heil, E. Langereis, M. C. M. van de Sanden, and W. M. M. Kessels, Appl. Phys. Lett. 89, 042112 (2006).

${ }^{41}$ A. S. Gudovskikh, J.-P. Kleider, J. Damon-Lacoste, P. Roca i Cabarrocas, Y. Veschetti, J.-C. Muller, P.-J. Ribeyron, and E. Rolland, Thin Solid Films 511-512, 385 (2006).

${ }^{42}$ J. Yuan, H. Shen, H. Huang, and X. Deng, J. Appl. Phys. 110, 104508 (2011). 
${ }^{43}$ L. Schmidt-Mende and J. L. MacManus-Driscoll, Materials Today 10, 40 (2007).

${ }^{44}$ G. K. Paul, Y. Nawa, H. Sato, T. Sakurai, and K. Akimoto, Appl. Phys. Lett. 88, 141901 (2006).
${ }^{45}$ A. Mittiga, F. Biccari, and C. Malerba, Thin Solid Films 517, 2469 (2009).

${ }^{46}$ K. Mizuno, M. Izaki, K. Murase, T. Shinagawa, M. Chigane, M. Inaba, A. Tasaka, and Y. Awakura, J. Electrochem. Soc. 152, C179 (2005). 